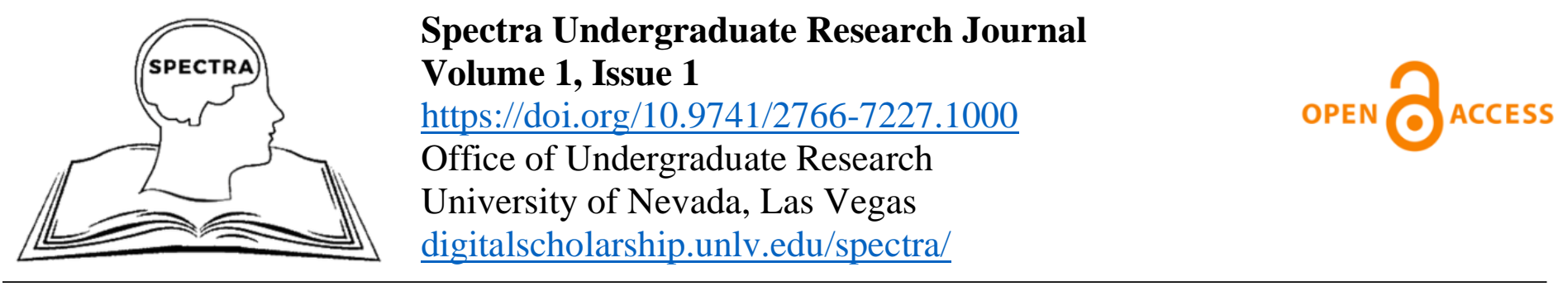

\begin{tabular}{|c|}
\hline Category \\
\hline Arts, Humanities, and Social Sciences $>$ Business $>$ Economics \\
\hline Received \\
\hline July 14,2020 \\
\hline Accepted \\
\hline January 18,2021 \\
\hline Published \\
\hline February 26, 2021 \\
\hline Article Title \\
\hline $\begin{array}{l}\text { The Effects of Renewable Portfolio Standards and the Deregulation of Energy Markets on Electricity } \\
\text { Prices }\end{array}$ \\
\hline Author \\
\hline Amani Chaar $(\mathrm{AC})^{1 *}$ \\
\hline Author Affiliation \\
\hline${ }^{1}$ Department of Economics, University of Nevada, Las Vegas, Las Vegas, NV, USA. \\
\hline Corresponding Author \\
\hline *Amani Chaar, chaar@unlv.nevada.edu \\
\hline Author Contributions \\
\hline $\begin{array}{l}\text { AC: Contributed conceptualization, data collection, drafting of paper, formal analysis, methodology, } \\
\text { and editing of manuscript }\end{array}$ \\
\hline Copyright \\
\hline $\begin{array}{l}\text { (C) } 9 \text { Articles in Spectra are freely available under a Creative Commons Attribution } \\
\text { License (CC BY 4.0) which allows others to re-use the work without permission as } \\
\text { long as the work is properly cited. }\end{array}$ \\
\hline ISSN \\
\hline $2766-7227$ \\
\hline Data Availability Statement \\
\hline $\begin{array}{l}\text { The author of this article confirms that all included literature review information is fully available } \\
\text { without restrictions. }\end{array}$ \\
\hline Conflicts of Interest \\
\hline The author declares that no conflicts of interest exist. \\
\hline Ethical Considerations \\
\hline $\begin{array}{l}\text { Given that this project did not involve human or animal subjects, no IRB or IACUC approval was } \\
\text { needed. No data are presented in this paper derived from the participants and all program elements } \\
\text { are publicly shared. }\end{array}$ \\
\hline Funding \\
\hline No funding was used to conduct this research. \\
\hline Recommended Citation \\
\hline $\begin{array}{l}\text { Chaar, A. (2021). The effects of renewable portfolio standards and the deregulation of energy markets } \\
\text { on electricity prices. Spectra Undergraduate Research Journal, } 1(1), \quad 1-15 . \\
\text { https://doi.org/10.9741/2766-7227.1000 }\end{array}$ \\
\hline
\end{tabular}




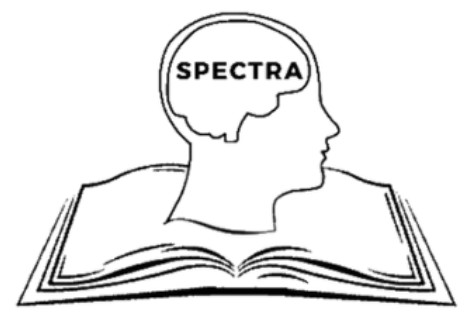

Spectra Undergraduate Research Journal

Volume 1, Issue 1, pp. 1-15

https://doi.org/10.9741/2766-7227.1000

Office of Undergraduate Research

University of Nevada, Las Vegas

digitalscholarship.unlv.edu/spectra/

\title{
The Effects of Renewable Portfolio Standards and the Deregulation of Energy Markets on Electricity Prices
}

Amani Chaar ${ }^{1}$

Author Affiliation:

${ }^{1}$ Department of Economics, University of Nevada, Las Vegas, Las Vegas, NV, USA.

\begin{abstract}
Renewable Portfolio Standards (RPS) are public policies put into effect to help alleviate the harmful consequences of air pollution. Every state has a unique form of standards corresponding to their natural resources. More states have implemented the policy to increase the generation of renewable energy; however, many stand opposed to the policy in fear that it will increase electricity prices. The influence that RPS has on the price of electricity is not entirely understood. Previous literature confirms that RPS, on average, increases prices by three percent. This paper focuses on analyzing the effect of RPS on electricity rates over a longer period. Furthermore, it incorporates the effect of various forms of energy deregulation across state energy markets. Results confirm that RPS does increase electricity rates in states with regulated energy markets; however, the implementation of retail choice and wholesale market access reverses these findings and decreases electricity prices overall. Individuals across the country will be able to make a more informed decision on public policies related renewable energy with this analysis.
\end{abstract}

Keywords: Renewable energy, Sustainability, Renewable portfolio standards, Electricity prices, Deregulation, Public policy

Renewable Portfolio Standards (also known as RPS) are an example of a command-and-control regulation implemented throughout many US states. An RPS is defined as a "requirement on retail electric suppliers to supply a minimum percentage or amount of its retail load with eligible sources of renewable energy" (Barbose, 2017, p. 5). Each state has its own unique RPS that affects different types of electric utilities and has different compliance requirements. By 2017, twenty-nine states and Washington D.C. have implemented RPS regulations in order to diversify energy sources, promote innovation and economic development, and reduce emissions (National Conference of State Legislatures [NCSL], 2018). Eight other states have implemented a "voluntary" renewable energy standard, or target that is not legally binding
(NCSL, 2018). These states are represented by a lighter green color in Figure 1, and will not be incorporated into the analysis while the grey states have neither an RPS nor renewable energy target.

Deregulation is characterized in a few different ways. If electric utilities have access to wholesale markets, they may be able to decrease retail prices. This is one way a state may allow for deregulation; the other option is to permit retail choice within the state. Retail choice allows consumers to select any provider for their electricity; without it, there is a monopoly on electricity. Craig and Savage (2013) define full competition as having access to both wholesale and retail choice within a state. This paper examines all three types of deregulation, retail choice, access to 
wholesale markets, or both-full competition, as a form of deregulation in its analysis.

Of the twenty-nine states that have an RPS mandate, fifteen of them have a fully deregulated electricity market. These states include: California, Connecticut, Delaware, Illinois, Massachusetts, Maryland, Maine, Michigan, New Hampshire, New Jersey, New York, Ohio, Pennsylvania, Rhode Island, and Texas (Zummo, 2018). The exact year of deregulation for each of the following states' energy markets, along with the years that they adopted RPS can be seen in Table 1. Some states, such as Virginia, have a deregulated market and no RPS, while states like Nevada have an RPS with a regulated market. This provides the data set a wide range of variability in its sample size.

Sustainability is a rising issue that public policy makers and individuals are starting to care more about in recent years. This behavior encourages the implementation of policies that help promote the use of renewable energy sources over conventional fossil fuel substitutes within states. However, the progression of these policies is hindered if the public is discouraged by increasing prices. Every state designs its own set of RPS laws specific to its desired goals. The Database of State Incentives for Renewables \& Efficiency displays the RPS policies paired with its state on the map in Figure 2. More states may adopt the policy if made aware of the costs and benefits.

The regulation of electricity in some states may be slowing down sustainability measures, and the unknown effects of deregulating the market has made citizens in states such as Nevada uncertain on how to vote on ballot initiatives in its 2018 midterm elections. Nevada's energy market is monopolized by one provider, NV Energy. The 2018 midterm ballot questions asked citizens to vote on deregulating the state's energy markets and increasing the state's RPS requirement from $25 \%$ by 2025 to $50 \%$ by 2030 (Clark County Elections Department, 2018). ${ }^{1}$ The New York Times (2018) presents the results from the election to be "no" for a deregulated energy market and "yes" to an increased RPS initiative. The effects of voting "no" to deregulation is unknown when looking into what is

\footnotetext{
1 Full questions can be retrieved from: https://www.clarkcountynv.gov/election/Pages/2018_QuestsGen. $\underline{\operatorname{aspx}}$
}

Spectra Undergraduate Research Journal - 2021 - Volume 1, Issue 1 best for citizens in Nevada in regards to electricity prices. Nevada, however, is only one example of a state with a regulated electricity market and an RPS initiative.

This paper attempts to analyze what impact an RPS will have on electricity prices in states with a deregulated electricity market. Using a panel data set, data are collected from utilities across all fifty states dated from 1990 to 2017. There is a challenge when estimating data from states with an RPS and non-RPS states. Tra (2015) explains that electric utilities in RPS states have unobservable differences from those in other states, resulting in variations of electricity rates. This references how states with RPS have more renewable energy potential due to the prominent sunlight, wind, dams, etc. These unobserved differences might produce biased estimates when running an Ordinary Least Squares (OLS) regression (Tra, 2015).

Characteristics of an RPS: States adopting the Renewable Portfolio Standard mandate have goals that vary depending on geographic location and renewable energy availability. Neimeyer et al. (2009) explains that each state RPS is characterized differently depending on (1) eligible technologies, (2) the percentage generation/capacity requirements from renewable sources overtime, (3) special treatment of individual technologies, (4) the presence and level of an alternative compliance payment (ACP), and (5) credit multipliers for certain resources or geographies. The type of electric utilities affected by the RPS standard also vary per state. Affected utility ownership types include municipalities, cooperatives, and/or investor-owned companies. Some states have a more aggressive RPS program because of their access to low-cost renewable resources (Neimeyer et al., 2009). Lower costs allow those states to have a higher percentage generation capacity given a certain period of time because renewable energy resources are widely available. For example, Nevada's solar power potential makes it easier/more practical for the state to 
implement solar panels when compared to states like Alaska.

An RPS is a binding regulation which requires states to implement ways to enforce it. It is a form of a command-and-control policy that is unlikely to result naturally through market competition. Grossman and Cole (1999) explain how many believe that commandand-control policies are less efficient or completely inefficient because they produce a greater social cost than benefit. RPS mandates are more expensive to impose on certain utilities, so states must ensure that utilities will comply with the standard. States do this by having mandates backed by a penalty. Tra (2015) explains the three options a utility has in order to comply with a states' RPS mandate: (1) own a facility that uses approved renewable energy sources to produce electricity, (2) purchase electricity from a renewable energy facility, and (3) purchase Renewable Energy Credits (RECs). ${ }^{2}$ In some states, a utility that does not meet the goal set by the state is subjected to a penalty known as an alternative compliance payment (ACP) (Solar Energy Industry Association (SEIA), 2013). If an electric utility does not comply, it will be forced to pay the compliance fee. The Solar Energy Industry Association (2013) mentions that utilities may also purchase RECs that can be traded to meet a state's RPS. The REC prices are based on ACP rates and current/expected supply-demand balance, which makes them volatile and sensitive to changes in eligibility rules (Barbose, 2017). Since every RPS mandate is different, state characteristics play a role in defining why specific standards and rules for an RPS are created.

Characteristics of Deregulation: Energy deregulation is a broad term that can be defined in different ways. Energy markets are supplied by vertically-integrated utilities that monopolized energy generation within their geographic area (Craig \& Savage, 2013). Recently, some of these markets are being restructured to allow for market competition amongst utilities. Wholesale electricity sales are allowed in some states as well, regulated by the Federal Energy Regulatory Commission (FERC). Market restructuring began with the Federal Energy Policy Act of 1992 and FERC Order No. 888 in 1996 (Craig \& Savage, 2013). The
Federal Energy Act created wholesale generators that sell and generate electricity at the wholesale level, and they provided FERC the ability to grant powerproducers the use of transmission lines from any entity to provide electricity to wholesale customers. States were also exposed to retail competition that allowed consumers to buy electricity from different retailers. Craig and Savage (2013) explain that the competitive wholesale and retail forces are supposed to incentivize managers to increase efficiency and become more innovative to decrease their costs. As previously stated, the estimator will classify deregulation as either accessibility to retail choice, wholesale markets, or both.

When it comes to the various ownership types in the analysis, cooperatives and municipalities are less likely to be exposed to, or affected by, deregulation in states that have allowed for it. Nueces Electric Cooperative (2018) distinguishes the three different utility ownership types. They define an investor-owned utility as a business organization that provides a product or service as a utility but is also managed as a private enterprise. Municipalities are run by city governments that are responsible for providing the utility-related service; Cooperatives, located in rural areas, belong to the people they serve and also share excess revenue with those people (Nueces Electric Cooperative, 2018). In the state of Texas, municipalities and cooperatives are exempt from deregulation and have the right to choose to participate in the retail electric market if they vote to. The Public Utility Commission of Texas (2019) states that although customers of municipalities and cooperatives do not have an actual role in managing their utility, they can elect the people that run them and voice their opinion. Cooperatives and municipalities, however, may have no motive to switch to a deregulated market since free market competition may not greatly benefit them. This is because cooperatives are run by the people who are a part of them, and municipalities are publicly owned; thus, the effect of deregulation may not be accurately predicted for these ownership types. For this reason, the analysis will focus primarily on deregulation's effect on investor-owned utilities.

\footnotetext{
2 Approved renewable energy sources can be found by state at: http://programs.dsireusa.org/system/program
}

Spectra Undergraduate Research Journal - 2021 - Volume 1, Issue 1 
Literature Review: There are concerns regarding the efficiency and costliness of an RPS. The first RPS mandate dates back to 1983 in Iowa (Barbose, 2017). The purpose of this mandate is to increase renewable energy sources used by each state to help reverse the effects of climate change. However, even with these new initiatives, there have been no major improvements with emission trends based on the most recent data, and nations are adopting minimal policies in an attempt to slow the effects of climate change (Nordhaus, 2018). Opponents of RPS standards believe the policy is ineffective in reducing emissions because the mandate is not universally applied across the states, does not address externalities directly, specifies a technology instead of emissions performance, and applies uniquely to one sector (Montgomery, 2005). Even though these inefficiencies occur, there are benefits from implementing the policy. Barbose et al. (2016) state that carbon dioxide was cut by 59 million metric tons (worth about $\$ 2.2$ billion), $\$ 5.2$ billion was provided in health and environmental benefits, water withdrawals and consumption were reduced, and 200,000 gross domestic jobs were supported in 2013.

An RPS is known to be a more expensive way to lower emissions, but it is important to know by exactly how much the mandate would cost through increased electricity prices and who would be the most affected. RPS standards are shown to be about twice as costly in reducing greenhouse gases (GHG) than other sources, and renewable energy may be hard to procure with the restrictions that some state RPS mandates impose on firms (Lyon and Mayo, 2010). Tra (2015) estimated that utilities subjected to an RPS that serve the residential and commercial sectors have increases in electricity prices by 3 percent.

A contributing factor to these price changes associated with an RPS could be the deregulation of state energy markets. Many states with some form of deregulation have also adopted an RPS. ${ }^{3}$ However, a little more than half of states with an RPS do not have full deregulation (both wholesale access and retail choice). This variation will help provide clear results

\footnotetext{
${ }^{3}$ See Table 1 for a list of states and the years they adopted an RPS and types of deregulation
}

on the effects of deregulation in states with and without RPS.

\section{Empirical Methodology}

Data: The data used for this empirical analysis is retrieved from the U.S. Energy Information Administration (EIA) and the Database of State Incentives for Renewables and Efficiency (DSIRE). The EIA (2018) provides the revenue, sales, and customer count of electric utilities from 1990-2017 separated by residential, commercial, industrial, transportation, and "other" sectors within the U.S. The information is further separated by industry sector categories. ${ }^{4}$ This research focuses on the residential and commercial sectors. To find the average price per $\mathrm{kWh}$ for each utility, I divide the residential and commercial sectors' revenue by sales. Utilities are represented by their state, unique utility number, year, and ownership type.

The method used will consist of an OLS regression, which is a simple linear regression model. When the explanatory variable of the model (in this case the RPS) is correlated with the error term (the unobservable effects), the regression suffers from an endogeneity problem. To overcome this potential endogeneity problem, the analysis will rely on a fixedeffect estimator to identify the unobservable effect of an RPS mandate on utilities' electricity rates. It is also important to identify the time-invariant omitted characteristics and control for them to find the true unbiased effect that an RPS mandate has on electricity prices. An example of a time-invariant characteristic would be Nevada's solar energy potential. Not all states have as many sunny days as Nevada; therefore, not all states could effectively use this renewable resource. Nevada's solar potential also does not vary per year; it is a consistent state characteristic that may create bias results in our estimator. Tra (2015) states that using a group-specific fixed effect estimator will help to control for the problem; in this case, it will be a state-by-year fixed effect.

${ }^{4}$ Categories include: total electric industry, full-service providers, restructured retail service providers, energy-only providers, and delivery-only service

Spectra Undergraduate Research Journal - 2021 - Volume 1, Issue 1 
The data set contains a total of 63,087 observations. The number of electric utilities in this study is 2,622, from 1990-2017. There was a significant drop in utilities after 2011 from the EIA database, and the reason is due to an abbreviated version of the form to reduce the reporting burden for utilities. The smaller utilities are still available to incorporate into the data set; however, the residential and commercial sectors in the new files are not distinguishable from one another. Therefore, this drop of roughly 1,000 utilities after 2011 cannot be fixed, but it will be taken into consideration.

Utility companies located in more than one state create a potential problem with the results, so they are dropped from the analysis. The state Iowa will also be dropped from the data since its RPS was implemented at an earlier time than what is covered in this analysis. The data set is unbalanced, meaning not every utility appears within every year observed. I chose not to drop utilities that disappear after a certain time period (from possibly closing down or merging with another company) because it creates a selection bias. This means that the only utilities included in the data would be those that have survived throughout the time-period analyzed which may skew the results.

There are nine different types of electric utilities that can be found within states that may be subject to an RPS. ${ }^{5}$ Tra (2015) mentions that there are only three types of major utilities operating in all states, and they account for about 84 percent of all electricity sales. Therefore, the paper will only use data on those three types: investor-owned utilities, municipalities, and cooperatives. The DSIRE database provides information on variables that characterize the presence of an RPS, which utilities are affected by the RPS, and the type of energy market a state has (full deregulated energy market, wholesale accessibility only, retail choice only, or regulated market).

The variables that will be used in the analysis are listed and described in Table 2. The dependent variable will be the average electricity price of an electric utility provider that operates in a state in residential and commercial sectors. For these dependent variables, the natural log will be taken to normalize the distribution of the data.

\section{Table 2}

\section{Summary Statistics}

\begin{tabular}{|c|c|c|c|c|}
\hline Variables & Label & Obs & Mean & Std. Dev. \\
\hline rprice & residential price $(\mathrm{kWh})$ & 63,848 & .0931 & .0568 \\
cprice & commercial price $(\mathrm{kWh})$ & 63,177 & .0911 & .0899 \\
RPS & 1 if utility affected by RPS & 64,130 & .0812 & .2732 \\
wholesaledreg & 1 if utility has access to wholesale market & 64,130 & .4285 & .4949 \\
\hline retaildreg & 1 if utility has retail choice & 64,130 & .1519 & .3589 \\
\hline fulldreg & 1 if utility has both wholesale and retail deregulation & 64,130 & .1384 & .3454 \\
\hline ccust & commercial customers per utility & 63,177 & 3562 & 20670 \\
\hline rcust & residential customers per utility & 63,849 & 27355 & 160514 \\
\hline
\end{tabular}

Other covariates that will impact utility price are state characteristics that control for the diversity of electricity's demand and supply across state borders, such as the state fuel costs. Coal and natural gas are substitutes to renewable energy sources; therefore, their price has a significant impact on electricity prices within RPS states. Other important characteristics include a state's population and population density. States with larger populations have a larger demand.
However, a higher population density will result in lower capital costs and electricity rates (Tra, 2015). These state-by-state differences will be controlled for by using a state-by-year fixed effects estimator.

Since this paper will look for a consistent linear trend overtime for the outcomes of the regressions, the state-by-year fixed effects will be applied using continuous linear time trends (i.state\#c.year). Wolfers (2013) conducted a study analyzing divorce laws and

\footnotetext{
${ }^{5}$ Including: cooperatives, facility, federal, investor-owned, municipals, political subdivision, power marketer, state, and other
}

Spectra Undergraduate Research Journal - 2021 - Volume 1, Issue 1 
their correlated increase in divorce rates. In order to account for slow-moving social and demographic trends within each state, Wolfers included a statespecific linear time trend. This paper will also incorporate state-specific trends to control for price differences across states that might affect state motives for incorporating deregulation and RPS. One fear with using state-specific trends is that the results may be sensitive to their inclusion, creating an omitted variable bias (Wolfers, 2003). For this reason, each regression in this study will show results before and after the inclusion of state trends to interpret the magnitude of sensitivity the data may have.

Econometric Specification: This analysis will be modeled after Tra's (2015) study with the addition of data from 2012-2017, while also incorporating the deregulation of electricity markets in the model. A panel data set will be used for this type of analysis in order to control for the multiple changes within states over a period of time. The dependent variable in this study will be the natural log price of electricity from utilities in each state over time (Priceist), and there will be two separate regressions for each sector: log of residential price (lrpriceist) and $\log$ of commercial price (lcpriceist).

This study will include a fixed-effects estimator. Fixed-effects (FE) assumes that all unobserved utility characteristics that can influence the adoption of an RPS are time-invariant. The model will incorporate utility fixed effects (FE) in every regression by default to capture the time-invariant unobserved characteristics between each utility and remove them from the model. This will remove the utility-specific effect (utilityi) from the error term and only leave the idiosyncratic error term. (uist).

\section{Model}

The first objective is to observe how RPS alone will impact prices in both the residential and the consumer sectors. Using the panel data set, utility numbers will be the panel variable while year will be the time variable. The econometric equation is seen below:
Equation 1. RPS Effects on all Utilities

$\log$ price $_{\text {ist }}=\alpha_{1} R P S_{\text {ist }}+\alpha_{2}$ logcustomers $_{i s t}+$ Byear $_{t}+$ yownership $_{i}$ yyear $_{t}+$ Sstate $_{s} \times$ year $_{t}+$ Фutility $_{i}+u_{i s t}$

The model is linear with parameters $\alpha, \beta, \gamma$, and error term uist. When running a regression, one of the most important properties is the mean-independence assumption. The mean-independence assumption ensures that the unobserved characteristics of state utilities that influence the dependent variable (Priceist) are not also correlated with the adoption of an RPS regulation. This is guaranteed by the random selection of electric utilities in the sample. If this assumption fails, then the entire regression will be biased. The idiosyncratic error term (uist) must also be uncorrelated with the explanatory variables, in this case RPS and deregulation, throughout all time periods to ensure the model avoids this issue of strict endogeneity.

The error term (uist) will capture all the unobserved factors that are not controlled for in the equation. In addition, the regression will include year fixed effects (year) to control for national unobserved effects that are time-variant, ownership fixed effects (ownership $\mathrm{x}$ year) to control for time-variant differences among different ownership types, a state trend variable (state $\mathrm{x}$ year) to control for state unobserved factors that affect price trends and the likelihood of adopting rps or deregulation trends over time, the RPS dummy variable that equals 1 if affected by RPS, and the log of the customer count for both sectors to control for utility size. ${ }^{6}$ The results are listed below in Table 3 .

The second model will provide the primary results of this study. It will illustrate the effects of both RPS and different forms of deregulation on electricity rates, but this model will only include Investor-Owned utilities. The same fixed effects will be included with the exception of ownership fixed effects since only one ownership type will be included. The results for Equation 2 will be seen in Table 4.

due to perfect collinearity. Regardless, trends and state-by-year fixed effects were able to produce similar results.

\footnotetext{
${ }^{6}$ Tra uses state-by-year fixed effects instead of state trends; however, because deregulation does not vary within a state, state-by-year fixed effects kicks out observations in regression that include deregulation
} 
Equation 2. Effects of RPS and Deregulation on Investor-Owned Utilities

$\log$ price $_{i s t}=\alpha_{1}$ RPS $_{\text {ist }}+\alpha_{2}$ deregulation $_{i s t}+$ $\alpha_{3} R P S_{\text {ist }} \times$ deregulation de + $\alpha_{4}$ logcustomers $_{\text {ist }}+\beta$ jyear $_{t}+\delta$ state $_{s} \times$ year $_{t}+$ Фutility $_{i}+u_{\text {ist }}$

Results
Table 3 displays the first results of RPS on all electric utilities in the sample. Four regressions were run to include both sectors with and without state trends. The only significant value is found in the residential sector with state trends; it confirms that an RPS does increase electricity rates by 3.2 percent. Tra (2015) provides similar results explaining that an RPS increases electricity rates by 3 percent on average.

Table 3.

Effects of RPS on All Utilities

\begin{tabular}{|c|c|c|c|c|}
\hline & \multicolumn{2}{|c|}{ Residential Rate } & \multicolumn{2}{|c|}{ Commercial Rate } \\
\hline Variable & $\mathbf{I}$ & II & I & II \\
\hline RPS & $.028(.021)$ & $* * * .032(.007)$ & $.011(.021)$ & $.009(.008)$ \\
\hline$N$ & 63,087 & 63,087 & 63,088 & 63,088 \\
\hline$R^{\wedge} 2$ & .7713 & .7111 & .5788 & .5267 \\
\hline Utility-Fixed Effects & yes & yes & yes & yes \\
\hline State Trends & no & yes & no & yes \\
\hline
\end{tabular}

Note. Numbers represent shift in log of prices. $\mathrm{R}^{\wedge} 2$ shown is within R-squared from STATA. All results include utilityfixed effects to control for time-varying unobservable factors. Parentheses show robust standard errors. ${ }^{*} p$-value $<0.10$, $* * p$-value $<0.05, * * * p$-value $<0.01$

Table 4 illustrates the estimated effects of RPS and deregulation on investor-owned utilities with and without state trends. One important observation is that wholesale deregulation does not seem to be as significant on its own. In the commercial sector, full deregulation lowers costs by around 5.4 percent; however, RPS increases costs by 6.8 percent which results in an overall increase of just 1.4 percent. On the other hand, the residential sector shows that retail and full deregulation offset the increase in RPS by roughly 2 percent, leading to an overall decrease for residential consumers.

\section{Table 4:}

Effects of RPS and Deregulation on Investor-Owned Utilities

\begin{tabular}{|c|c|c|c|c|c|c|}
\hline & \multicolumn{6}{|c|}{ Commercial Rate } \\
\hline Variable & \multicolumn{2}{|c|}{ Wholesale } & \multicolumn{2}{|c|}{ Retail } & \multicolumn{2}{|c|}{ Full } \\
\hline RPS & $.029(.054)$ & $.030(.031)$ & $.061(.039)$ & $* * .075(.029)$ & $.060(.038)$ & $* * .068(.029)$ \\
\hline deregulation & $*_{-} .040(.023)$ & -.015 & $-.023(.023)$ & $-.019(.026)$ & $*_{-} .046(.023)$ & $* *-.054(.024)$ \\
\hline RPS*dreg & $.005(.059)$ & $.035(.032)$ & $-.074(.063)$ & $*-.070(.042)$ & $-.056(.064)$ & $-.043(.042)$ \\
\hline$N$ & 3,142 & 3,142 & 3,142 & 3,142 & 3,142 & 3,142 \\
\hline$R^{2}$ & .5248 & .6315 & .5277 & .6329 & .5286 & .6335 \\
\hline Utility-Fixed Effects & yes & yes & yes & yes & yes & yes \\
\hline \multirow[t]{2}{*}{ State Trends } & no & yes & no & yes & no & yes \\
\hline & \multicolumn{6}{|c|}{ Residential Rate } \\
\hline Variable & \multicolumn{2}{|c|}{ Wholesale } & \multicolumn{2}{|c|}{ Retail } & \multicolumn{2}{|c|}{ Full } \\
\hline RPS & $.023(.051)$ & $.019(.026)$ & $.056(.037)$ & *.056(.027) & $.059(.036)$ & $* .057(.026)$ \\
\hline deregulation & $* *-.058(.021)$ & $* *-.042(.016)$ & $*-.057(.022)$ & $* * *-.076(.020)$ & $* *-.062(.021)$ & $* * *-.079(.019)$ \\
\hline RPS *dreg & $.033(.054)$ & $* .064(.029)$ & $-.021(.057)$ & $-.010(.035)$ & $-.022(.058)$ & $.003(.035)$ \\
\hline$N$ & 3,141 & 3,141 & 3,141 & 3,141 & 3,141 & 3,141 \\
\hline$R^{2}$ & .5748 & .6628 & .5752 & 6639 & .5757 & .6637 \\
\hline Utility-Fixed Effects & yes & yes & yes & yes & yes & yes \\
\hline State Trends & no & yes & no & yes & no & yes \\
\hline
\end{tabular}

Spectra Undergraduate Research Journal - 2021 - Volume 1, Issue 1 
Note. Numbers represent shift in $\log$ of prices. $\mathrm{R}^{\wedge} 2$ shown is within R-squared from STATA. All results include utilityfixed effects to control for time-varying unobservable factors. Parentheses show robust standard errors. ${ }^{*} p$-value $<0.10$, $* *$ p-value $<0.05, * * * p$-value $<0.01$

\section{Discussion}

Public policies are intended to promote general welfare. RPS is expected to increase electricity prices due to the costliness of generating renewable energy along with the costs of cheaper substitutes. With electricity prices going up with the integration of renewable portfolio standards, the public is likely to vote against the policy. However, deregulation is expected to increase market competition which in turn creates lower prices for consumers and promotes innovation that leads to greater efficiency. This is definitely the case when it comes to investor-owned utilities. The public is more likely to support RPS and its benefits towards the environment if it also lowers electricity prices. This support will allow policy makers to decrease negative externalities - like air pollution - in the environment while lowering costs for consumers. It is also interesting to note that the residential sector benefits more from retail and full deregulation than the commercial sector. Since corporations are expected to engage in market competition, it is more likely that innovation and the desire to maximize profits would benefit corporations more. The results, however, reveal the opposite. This makes residential consumers the target audience for the benefit associated with RPS and full deregulation.

Knowledge of the potential benefits of combining RPS with full market competition allows consumers to make well informed decisions on state policies. The state of Nevada is among those that chose not to deregulate its energy markets, yet the RPS mandate may also be increasing its requirement within the next year. This could only mean that prices will probably increase for consumers in the residential and commercial sectors. The increase in electricity prices could be offset with full market competition, but the public needs to be made aware of this potential benefit.

\section{Conclusion}

Overall, implementing an RPS may lead to electricity price increases. Yet, states that have implemented retail choice or full competition have managed to offset these increases and not feel the social costs of the policy. The state of Nevada is among those that chose not to deregulate its energy markets, yet the RPS mandate may also be increasing its requirement within the next year. This could only mean that prices will increase for consumers in the residential and commercial sectors.

Public policy makers should make the correlation between RPS and deregulation clearer for individuals. This will encourage voters to make more informed decisions on what they want and allow policy makers to create better policies that will counteract negative externalities caused by fossil fuels. When integrating a method that promotes environmental sustainability and the general welfare of the people, public policy will be able to resolve environmental concerns without the costs associated with it.

\section{References}

Barbose, G. (2017). U.S. Renewables Portfolio Standards.

Retrieved from emp.lbl.gov/projects/renewablesportfolio/

Barbose, G., Bird, L., Heeter, J., Flores-Espino, F., \& Wiser, R. (2015). Costs and benefits of renewables portfolio standards in the United States. Renewable and Sustainable Energy Reviews, 52, 523-533. doi:10.1016/j.rser.2015.07.175

Barbose, G., Wiser, R., Heeter, J., Mai, T., Bird, L., Bolinger, M., . . . Millstein, D. (2016). A retrospective analysis of benefits and impacts of U.S. renewable portfolio standards. Energy Policy, 96, 645660. doi:10.1016/j.enpol.2016.06.035

Clark County Elections Department. (2018, September 26). Ballot Questions - 2018 Gen. Election. Retrieved

from www.clarkcountynv.gov/election/Pages/ 2018_QuestsGen.aspx

Craig, J., \& Savage, S. (2013). Market Restructuring, Competition and the Efficiency of Electricity Generation: Plant-level Evidence from the 
United States 1996 to 2006. The Energy Journal, 34(1), 1-31.

Database of State Incentives for Renewables and Efficiency, (DSIRE). (2018). Programs. Retrieved from http://programs.dsireusa.org/system/program

Energy Information Administration (EIA). (1996). State energy data report 1994: Consumption estimates. Data Planet. doi:10.2172/434861

Energy Information Administration (EIA). (2018). Independent Statistics and Analysis. Retrieved February 02, 2019, from www.eia.gov/electricity/sales_revenue_price/

Grossman, P. Z., \& Cole, D. H. (1999). When Is Command-and-Control Efficient? Institutions, Technology, and the Comparative Efficiency of Alternative Regulatory Regimes for Environmental Protection. Retrieved from www.repository.law.indiana.edu/cgi/viewcont ent.cgi? article $=1591 \&$ context $=$ facpub

Lips, B. (2018). Credit Multipliers In Renewable Portfolio Standards. Clean Energy States Alliance. Retrieved from www.cesa.org/assets/2018-Files/RPS-

Multipliers.pdf

Lyon, T. P., and H. Mayo. (2010) Why Do States Adopt Renewable Portfolio Standards: An Empirical Investigation. The Energy Journal, 31(3), 133-57.

Montgomery, D. W. (2005). Renewable Portfolio Standards A Solution In Search of Problem? Harvard Electricity Policy Group. Retrieved from https://hepg.hks.harvard.edu

National Conference of State Legislatures (NCSL). (2018). State Renewable Portfolio Standards and Goals. Retrieved from www.ncsl.org/research/energy/renewable -portfolio-standards.aspx

Neimeyer, M., Bloomberg, S., \& Ditzel, K. (2009). The Merits of Combining a Renewable Electricity Standard with a Greenhouse Gas Cap-andTrade Policy: An Analysis of the American Clean Energy and Security Act of 2009. Dialogue, 17(2), 17-20.
Nordhaus, W. (2018). Projections and Uncertainties About Climate Change in an Era of Minimal Climate Policies. American Economic Journal: Economic Policy, 10(3). doi:10.3386/w22933

Nueces Electric Cooperative. (2018). About Deregulation. Retrieved from www.nueceselectric.org/content/aboutderegulation

Public Utility Commission of Texas. (2019). Municipally-Owned Electric Utilities and Electric Cooperatives FAQs. Retrieved from www.puc.texas.gov/consumer/facts/faq/ Muni.aspx

Solar Energy Industry Association (SEIA). (2013). RPS Solar Carve Out, Colorado. Retrieved from www.seia.org/researchresources/rps-solar-carve-out-colorado

The New York Times. (2018, November 06). Nevada Election Results. Retrieved from www.nytimes.com/interactive/2018/11/0 6/us/elections/results-nevada-elections.html

Tra, C. I. (2015). Have Renewable Portfolio Standards Raised Electricity Rates? Evidence From U.S. Electric Utilities. Contemporary Economic Policy,34(1),

$184-$

189. doi:10.1111/coep.12110

U.S. Energy Information Administration - EIA Independent Statistics and Analysis. (2018, September 25). Retrieved from www.eia.gov/electricity/monthly/

Wolfers, J. (2003). Did Unilateral Divorce Laws Raise Divorce Rates? A Reconciliation and New Results. doi:10.3386/w10014

Zummo, P. (2018, May). Retail Electric Rates in Deregulated and Regulated States. Retrieved from www.publicpower.org/system/files/documents /Retail-Electric-Rates-in-Deregulated-States2017-Update\%20(003).pdf 
Appendix A: Figure 1. U.S. State Renewable Energy Initiatives

\section{States and territories with \\ Renewable Portfolio Standards}

States and territories with a
States and territories with no

standard or target

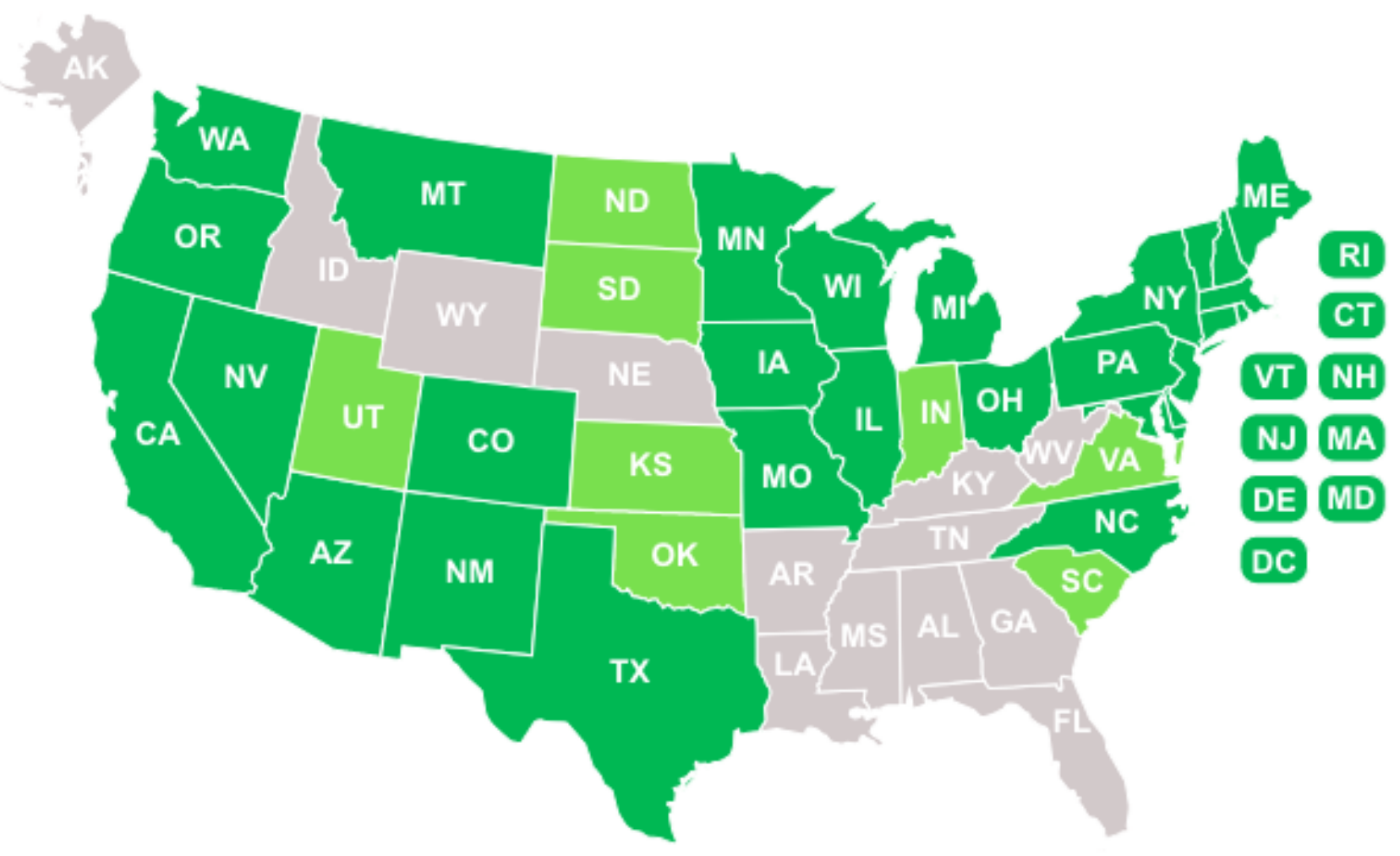

\section{HI}

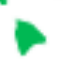

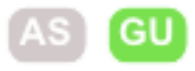

\section{MP PR VI}

Source: National Conference of State Legislatures (NCSL), (2018). 
Appendix B: Figure 2. Map of RPS Policies in the U.S.
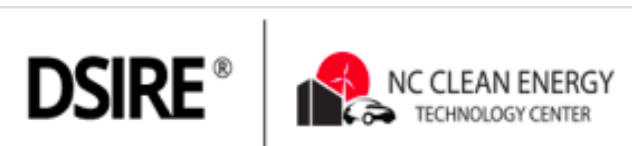

\section{Renewable Portfolio Standard Policies}

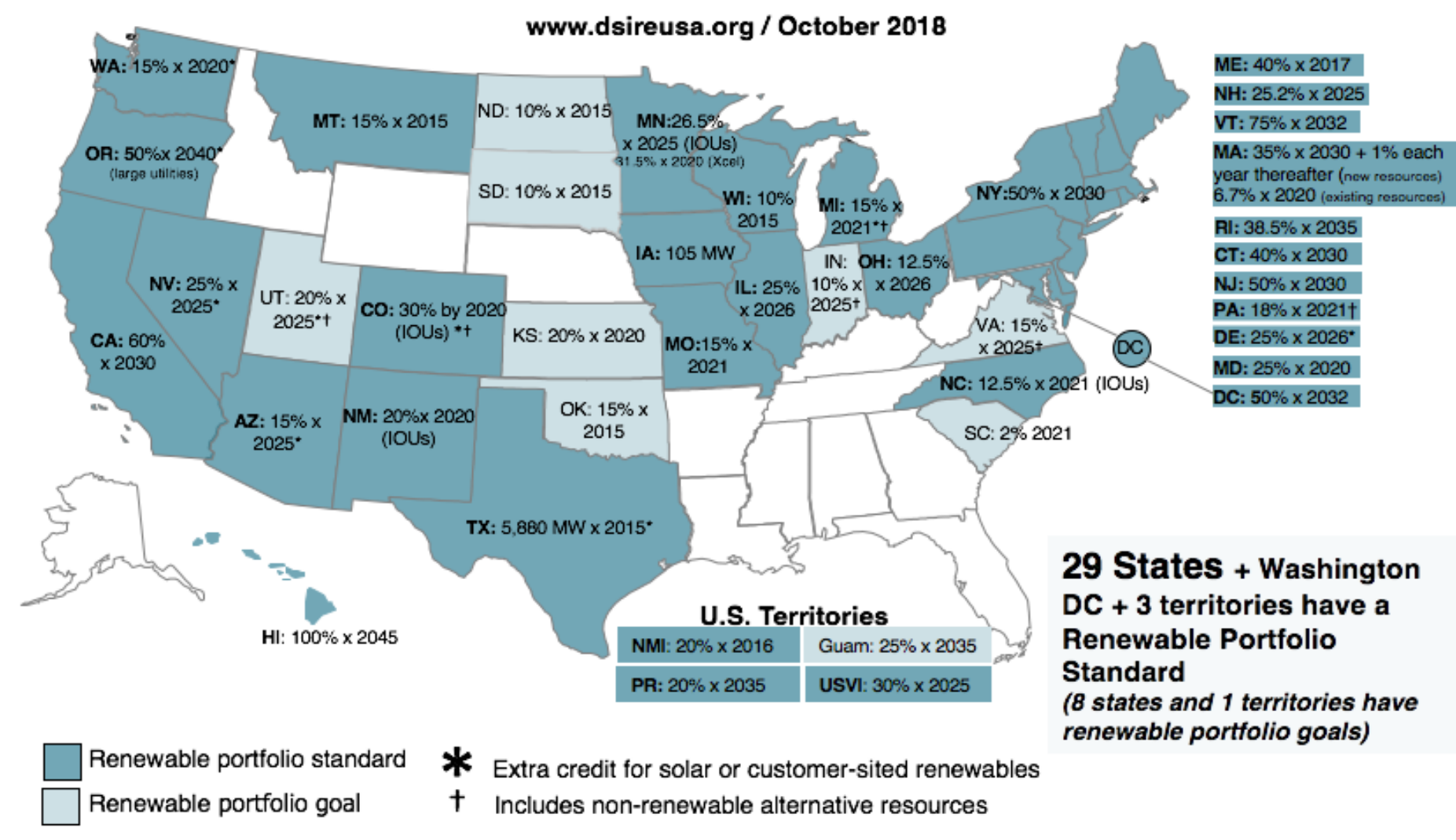

Source: Database of State Incentives for Renewables and Efficiency, (DSIRE), (2018). 
Appendix C: Table 1. RPS and Deregulation State and Year

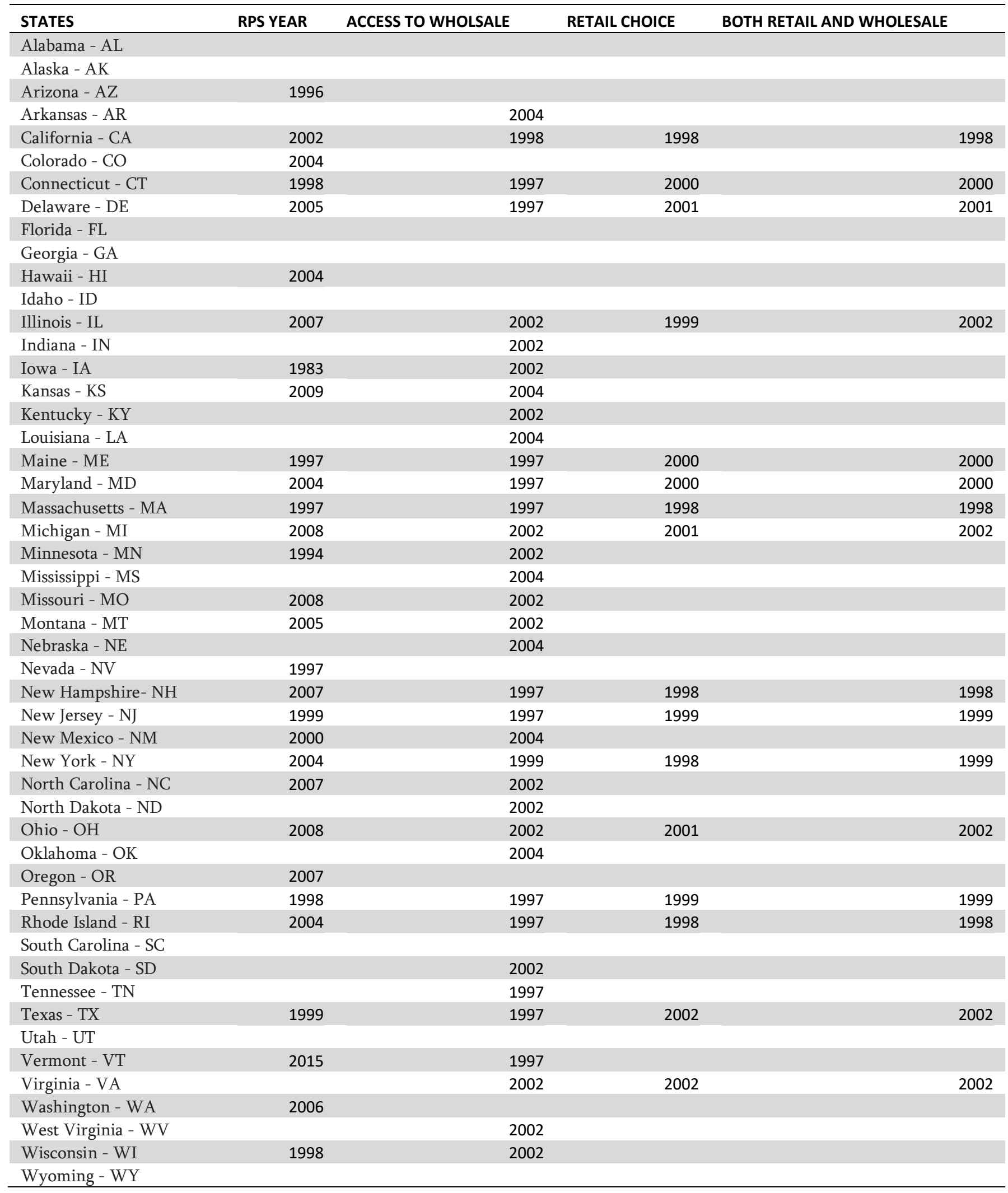


Appendix D: Table 2. Summary Statistics

\begin{tabular}{|c|c|c|c|c|}
\hline Variables & Label & Obs & Mean & Std. Dev. \\
\hline rprice & residential price $(\mathrm{kWh})$ & 63,848 & .0931 & .0568 \\
cprice & commercial price $(\mathrm{kWh})$ & 63,177 & .0911 & .0899 \\
RPS & 1 if utility affected by RPS & 64,130 & .0812 & .2732 \\
wholesaledreg & 1 if utility has access to wholesale market & 64,130 & .4285 & .4949 \\
retaildreg & 1 if utility has retail choice & 64,130 & .1519 & .3589 \\
fulldreg & 1 if utility has both wholesale and retail deregulation & 64,130 & .1384 & .3454 \\
ccust & commercial customers per utility & 63,177 & 3562 & 20670 \\
rcust & residential customers per utility & 63,849 & 27355 & 160514 \\
\hline
\end{tabular}


Appendix E: Table 3: Effects of RPS on All Utilities

\begin{tabular}{|c|c|c|c|c|}
\hline \multirow[b]{2}{*}{ Variable } & \multicolumn{2}{|c|}{ Residential Rate } & \multicolumn{2}{|c|}{ Commercial Rate } \\
\hline & I & II & $\mathbf{I}$ & II \\
\hline RPS & $.028(.021)$ & $* * * .032(.007)$ & $.011(.021)$ & $.009(.008)$ \\
\hline$N$ & 63,087 & 63,087 & 63,088 & 63,088 \\
\hline$R^{\wedge} 2$ & .7713 & .7111 & .5788 & .5267 \\
\hline Utility-Fixed Effects & yes & yes & yes & yes \\
\hline State Trends & no & yes & no & yes \\
\hline
\end{tabular}

Note. Numbers represent shift in log of prices. $\mathrm{R}^{\wedge} 2$ shown is within R-squared from STATA. All results include utility-fixed effects to control for time-varying unobservable factors. Parentheses show robust standard errors. $*$-value $<0.10$, ** p-value $<0.05$, ***p-value $<0.01$ 
Appendix F: Table 4. Effects of RPS and Deregulation on Investor-Owned Utilities

\begin{tabular}{|c|c|c|c|c|c|c|}
\hline \multirow[b]{2}{*}{\begin{tabular}{|l} 
Variable \\
\end{tabular}} & \multicolumn{6}{|c|}{ Commercial Rate } \\
\hline & \multicolumn{2}{|c|}{ Wholesale } & \multicolumn{2}{|c|}{ Retail } & \multicolumn{2}{|c|}{ Full } \\
\hline RPS & $.029(.054)$ & $.030(.031)$ & $.061(.039)$ & $* * .075(.029)$ & $.060(.038)$ & $* * .068(.029)$ \\
\hline deregulation & $*_{-} .040(.023)$ & -.015 & $-.023(.023)$ & $-.019(.026)$ & $*_{-} .046(.023)$ & $* *-.054(.024)$ \\
\hline RPS*dreg & $.005(.059)$ & $.035(.032)$ & $-.074(.063)$ & $*-.070(.042)$ & $-.056(.064)$ & $-.043(.042)$ \\
\hline$N$ & 3,142 & 3,142 & 3,142 & 3,142 & 3,142 & 3,142 \\
\hline$R^{2}$ & .5248 & .6315 & .5277 & .6329 & .5286 & .6335 \\
\hline Utility-Fixed Effects & yes & yes & yes & yes & yes & yes \\
\hline \multirow[t]{2}{*}{ State Trends } & no & yes & no & yes & no & yes \\
\hline & \multicolumn{6}{|c|}{ Residential Rate } \\
\hline Variable & \multicolumn{2}{|c|}{ Wholesale } & \multicolumn{2}{|c|}{ Retail } & \multicolumn{2}{|c|}{ Full } \\
\hline RPS & $.023(.051)$ & $.019(.026)$ & $.056(.037)$ & $\star .056(.027)$ & $.059(.036)$ & $* .057(.026)$ \\
\hline deregulation & $* *-.058(.021)$ & $* *-.042(.016)$ & $*-.057(.022)$ & $* * *-.076(.020)$ & $* *-.062(.021)$ & $* * *-.079(.019)$ \\
\hline RPS*dreg & $.033(.054)$ & $* .064(.029)$ & $-.021(.057)$ & $-.010(.035)$ & $-.022(.058)$ & $.003(.035)$ \\
\hline$N$ & 3,141 & 3,141 & 3,141 & 3,141 & 3,141 & 3,141 \\
\hline$R^{2}$ & .5748 & .6628 & .5752 & .6639 & .5757 & .6637 \\
\hline Utility-Fixed Effects & yes & yes & yes & yes & yes & yes \\
\hline State Trends & no & yes & no & yes & no & yes \\
\hline
\end{tabular}

Note. Numbers represent shift in $\log$ of prices. $\mathrm{R}^{\wedge} 2$ shown is within R-squared from STATA. All results include utility-fixed effects to control for time-varying unobservable factors. Parentheses show robust standard errors. $* p$-value $<0.10$, **p-value $<0.05, * * * p$-value $<0.01$ 